\title{
Lack of 'tissue' transglutaminase protein cross-linking leads to leakage of macromolecules from dying cells: relationship to development of autoimmunity in MRLIpr/Ipr mice
}

\author{
Lucia Piredda ${ }^{1}$, Alessandra Amendola ${ }^{1}$, Vittorio Colizzi ${ }^{1}$, \\ Peter J.A. Davies ${ }^{2}$, Maria Grazia Farrace ${ }^{1}$, Maurizio \\ Fraziano $^{1}$, Vittorio Gentile ${ }^{3}$, Ivan Uray ${ }^{4}$, Mauro Piacentini ${ }^{1,5}$ \\ and Laszlo Fesus ${ }^{4}$ \\ 1 Department of Biology, University of Rome 'Tor Vergata', Rome, Italy \\ 2 Department of Pharmacology, University of Texas, Medical School at Houston, \\ Texas, USA \\ ${ }^{3}$ Department of Biochemistry and Biophysic, II University of Naples, Italy \\ ${ }^{4}$ Department of Biochemistry, University Medical School of Debrecen, \\ Debrecen, Hungary \\ 5 corresponding author: Department of Biology, University of Rome 'Tor \\ Vergata', Via della Ricerca Scientifica 1, 00133 Rome, Italy. \\ tel: (396) 72594370; fax: (396) 2023500
}

Received 5.3.97; revised 5.4.97; accepted 15.4.97

Edited by P. Cohen

\begin{abstract}
Genetic defects of the CD95 (Fas/Apo-1) receptor/ligand system, has recently been involved in the development of human and murine autoimmunity. We investigated whether a deregulation of the 'tissue' transglutaminase (tTG), a multifunctional enzyme which is part of the molecular program of apoptosis, may act as a cofactor in the development of autoimmunity. We found that MRL/pr/lpr, which are characterized by a defect in the CD95 receptor and suffer of a severe systemic lupus erythematosus-like disease, produce large amounts of circulating tTG autoantibodies. This phenomenon is paralleled by an abnormal accumulation of an inactive enzyme protein in the accessory cells of lymphoid organs. To investigate the molecular mechanisms by which $\mathrm{TTG}$ inhibition may contribute to the development of autoimmunity we generated a cell culture model system consisting of $L 929$ cells stably transfected with a full length tTG CDNA. When L929 cells were killed by Tumor Necrosis Factor $\alpha(T N F)$ a pronounced release of DNA and Lactate Dehydrogenase (LDH) was observed. Overexpression of $\mathrm{tTG}$ in these cells largely prevented the leakage of macromolecules determined by TNF $\alpha$ treatment, an effect which is abolished by inactivating the enzyme cross-linking activity by a synthetic inhibitor. These in vitro observations provided the basis to explain the increased levels of plasmatic LDH we detected in MRL/pr/lpr mice. These data suggest that lack of an active ITG may represent a cofactor in the development of autoimmunity.
\end{abstract}

Keywords: apoptosis, follicular dendritic cells, lymph nodes, autoantibody, $\mathrm{LDH}, \mathrm{TNF} \alpha$
Abbreviations: tTG, 'tissue' transglutaminase; TNF $\alpha$, tumor necrosis factor $\alpha$; LDH, lactate dehydrogenase; HSP, heat shock protein; LC1, lipocortin-1; APC, antigen presenting cell; PLC, phospholipase-C; PBS, phosphate buffer saline; SSC, standard saline citrate; Ipr, lymphoproliferative gene.

\section{Introduction}

'Tissue' transglutaminase (tTG; E.C. 2.3.2.13) is a multifunctional protein which, in its protein cross-linking configuration, catalyzes a $\mathrm{Ca}^{2+}$ and thiol-dependent acyltransfer reaction among polypeptide chains, forming $\varepsilon(\gamma$ glutamyl)lysine and $\mathrm{N}, \mathrm{N}$-bis $(\gamma$-glutamyl)polyamine isodipeptide linkages (Folk, 1980; Fesus et al, 1991; Piacentini et al, 1994). The formation of these covalent cross-links leads to protein polymerization conferring resistance to physical stresses as well as insolubility (in SDS and chaotropic agents) to the polypeptides included into the polymer (Folk, 1980; Fesus et al, 1989, 1991; Piacentini et al, 1991, 1994).

Several laboratories have demonstrated the association between apoptosis and the induction and activation of tTG both in vivo and in vitro (see Fesus et al, 1991; Piacentini et al, 1994 for review). The covalent bonds formed by the tTG-catalyzed reactions in the apoptotic bodies are irreversible, in fact, endoproteases capable of hydrolyzing these cross-links have yet to be identified in vertebrates (Fesus et al, 1991; Piacentini et al, 1994). As a consequence free $\varepsilon(\gamma$-glutamyl)lysine, the degradation product of the tTG crosslinked polymers present in apoptotic bodies, is detectable both in the culture fluid and in plasma (Fesus et al, 1991; Harsalvi et al, 1992). Evidence has also been presented indicating that ITG might be involved in killing (Piacentini, 1995; Melino et al, 1994; Gentile et al, 1992; Wyllie et al, 1980).

One important feature distinguishing apoptosis from necrosis in vivo is that in the former there is an efficient disposal of apoptotic bodies which prevents both the inflammatory response and the exposure of self antigens which may lead to the development of autoimmunity (White, 1996).

MRL/Mp mice with a lymphoproliferative gene, Ipr (MRL/ Mp-Ipr/Ipr), develop severe autoimmune diseases such as lymphadenopathy, glomerulonephritis, arteritis and arthritis associated with an age-dependent massive production of autoantibodies which determine their premature death (Cohen and Eisenberg, 1991; Theofilopoulos, 1995; Nagata and Golstein, 1995). It has been demonstrated that the lymphoproliferation disorder described in the $I p r$ 
mice is characterized by a defect in the CD95 antigen that mediates apoptosis (Nagata and Golstein, 1995; WatanabeFukunaga, 1992). However, the pathogenesis of these autoimmune diseases cannot be explained by the lack of CD95-mediated apoptosis alone; the dysfunction of other gene products, particularly of those involved in the disposal mechanisms of apoptosis has also been hypothesized (Theofilopoulos, 1995). This study was undertaken to verify whether an impairment of tTG-catalyzed covalent polymerization of proteins in dying cells leads to the release of intracellular components and whether this phenomenon is related to the development of autoimmune syndromes such as that affecting MRL/pr/lpr mice.

\section{Results}

\section{Presence of autoantibodies against apoptosis- related gene products in MRLIpr/Ipr mice}

MRL/pr/lpr mice show an age-dependent increase in autoantibodies against the oligonucleosomes fragments produced

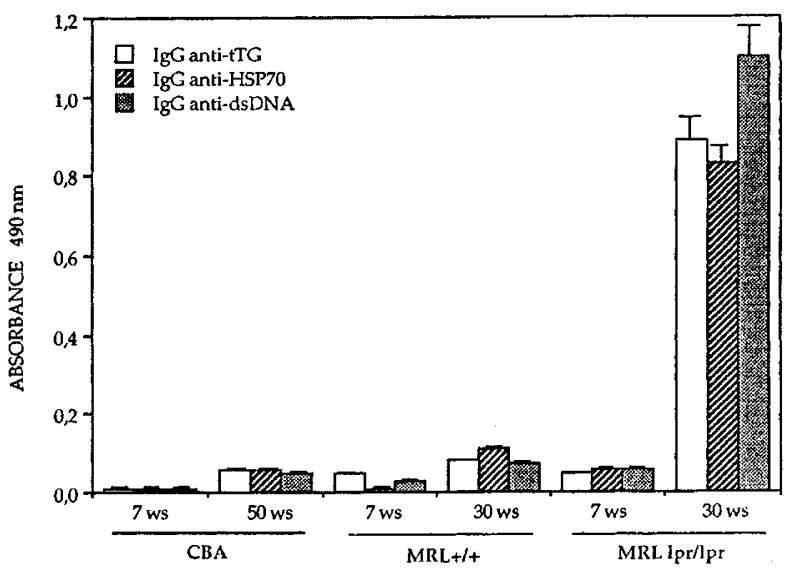

Figure 1 Presence of antibodies to tTG, HSP70 and dsDNA in MRL/pr/lpr mice. High levels of IgGs were detected only in the sera of 30-week-old MRL/pr/Ipr mice. ELISA assay was performed as described in Materials and Methods. Data were expressed as the mean \pm standard error (S.E.M.) of four determinations for each experimental group. by the activation of endonuclease(s) during apoptosis which is associated with the overproduction of several cytokines including TNF $\alpha$ (Cohen and Eisenberg, 1991, Theofilopoulos, 1995, Nagata and Golstein, 1995; Yokoyama et al, 1995; Tang etal, 1991; Levine etal, 1991; Izui etal, 1984). To verify whether additional abnormalities related to the cell death programme may have a role in the development of autoimmunity in MRL/pr/ Ipr mice, we first investigated the presence of serum autoantibodies against proteins and intracellular macromolecules produced during apoptosis.

Figure 1 shows that 30 week-old MRL/pr/lpr mice have high levels of anti-tTG and $70 \mathrm{kDa}$ Heat Shock Protein (HSP) IgGs whose synthesis is elevated in cells undergoing apoptosis (Buttyan et al, 1988).

\section{Accumulation of an inactive tTG in the lymphoid organs of aging MRL/pr/lpr mice}

In an attempt to investigate the abnormal production of anti-tTG antibody the expression of tTG in the lymph nodes and thymus of young (7 weeks) and old (30 weeks) MRL+/

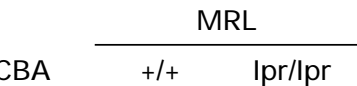

7ws 50ws 7ws 30ws 7ws 30ws

Thymus

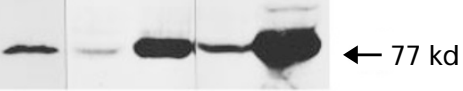

Lymph node

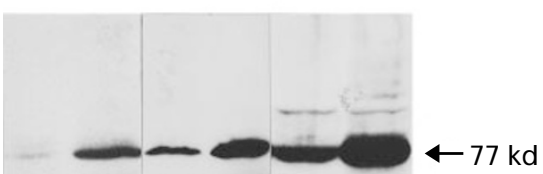

Figure 2 Effect of aging on TTG protein levels in thymuses and lymph nodes from CBA, MRL +/+ and MRL/pr/lpr mice. Thymuses and lymph nodes from $\mathrm{CBA}, \mathrm{MRL}+/+$ and MRL/pr/lpr mice at different ages were homogenized and Western blot analysis was carried out on aliquots $(100 \mu \mathrm{g})$ of the total protein extracts as described in Materials and Methods.

Table 1 Effect of aging on 'tissue' transglutaminase activity in thymus and lymph node of CBA, MRL+/+ and MRL/pr/lpr mice

\begin{tabular}{|c|c|c|c|c|c|c|c|}
\hline & \multirow{2}{*}{$\begin{array}{c}\text { Age } \\
\text { (weeks) }\end{array}$} & \multicolumn{3}{|c|}{ Thymus } & \multicolumn{3}{|c|}{ Lymph Node } \\
\hline & & $\mathbf{A}$ & B & $A / B^{*}$ & $\mathbf{A}$ & B & A/B \\
\hline \multicolumn{8}{|l|}{$\overline{\mathrm{CBA}}$} \\
\hline & 7 & $0.5 \pm 0.1$ & $1.0 \pm 0.3$ & $(0.5)$ & $0.7 \pm 0.4$ & $1.2 \pm 0.2$ & $(0.6)$ \\
\hline & 50 & $0.8 \pm 0.2$ & $1.6 \pm 0.3$ & $(0.5)$ & $1.5 \pm 0.5$ & $3.0 \pm 0.5$ & $(0.5)$ \\
\hline & 7 & $0.6 \pm 0.1$ & $1.0 \pm 0.3$ & $(0.6)$ & $0.5 \pm 0.2$ & $1.0 \pm 0.2$ & $(0.5)$ \\
\hline \multicolumn{8}{|l|}{$\mathrm{MRL}+/+$} \\
\hline & 30 & $2.3 \pm 0.7$ & $3.8 \pm 0.7$ & $(0.6)^{\circ}$ & $2.6 \pm 0.8$ & $6.5 \pm 1.2$ & $(0.4)^{\circ}$ \\
\hline & 7 & $0.7 \pm 0.1$ & $2.3 \pm 0.3$ & $(0.3)^{\circ}$ & $1.0 \pm 0.3$ & $5.0 \pm 0.9$ & $(0.2)^{\circ}$ \\
\hline & 30 & $2.3+0.5$ & $11.5+1.3$ & $(02)^{\circ}$ & $27+05$ & $135+0 ?$ & MRL/pr/lpr \\
\hline
\end{tabular}

(A) tTG enzymatic activity expressed as nmol/h/mg protein (B) tTG protein levels evaluated by densitometric analysis of Western blot analyses as reported in Figure 2 and expressed as arbitrary units. $\left(^{*}\right)$ The relative specific activity is reported in parenthesis, values have been calculated by dividing the above reported tTG enzymatic activities $(A)$ by the respective amount of enzyme protein (B). Data are the mean of triplcate determinations with a S.E.M. in four different experiments. $\left({ }^{\circ}\right)$ Statistically significant $(P<0.01)$ with respect to the relative CBA controls. 
+ and MRLIpr/lpr as well as of control mice (7 and 50 weeks old CBA mice) was analyzed. Figure 2 shows that the tTG gene is highly expressed in the thymus and lymph nodes both from MRL+/+ and MRL/pr/lpr as compared to control CBA mice. While a slight age-dependent increase was noticed in 50-week-old CBA mice, an abnormal accumulation of the tTG protein was detected both in the thymus and lympth nodes of 7-weeks and 30-week-old MRLIpr/lpr mice (Figure 2). However, the increase in the enzyme activity detected in MRL/pr/lpr mice (Table 1) does not match the enzyme protein level observed in the lymphoid tissues of the same animals (Figure 2). In fact, a significant early decrease in the relative specific activity of tTG (activity/antigen, Table 1) was observed in MRL/pr/ Ipr mice compared to that observed in $\mathrm{MRL}+/+$ and CBA mice, suggesting that an inactive tTG is present in MRL/pr/ Ipr mice. This hypothesis has been confirmed in vivo by measuring of tTG-dependent formation of the SDSinsoluble cross-linked polymers in lymphoid cells from MRL/pr/lpr mice at different ages and the accumulation in plasma of MRL/pr/lpr mice of free $\varepsilon(\gamma$-glutamyl)lysine (Fesus et al, 1991). Data reported in Figure 3 show that the age-dependent accumulation of tTG protein in cells extracted from the lymph nodes of MRL/pr/lpr mice was not paralleled by a proportional increase in the number of cross-linked protein scaffolds. In addition, no significative change in the plasma level $(1-2 \mu \mathrm{mol} / \mathrm{L})$ of $\varepsilon(\gamma$-glutamyl)lysine, which reflects the overall cross-linking activity in the body (Fesus et al, 1991; Harsalvi et al, 1992), was observed in MRL/pr/lpr when compared to CBA and MRL+/ + mice (data not shown). Taken together these data suggest that an inactive TTG is present in MRL/pr/lpr mice.

To determine whether the discrepancy observed between the accumulation of enzyme protein and its activity was associated with a rearrangement of the tTG

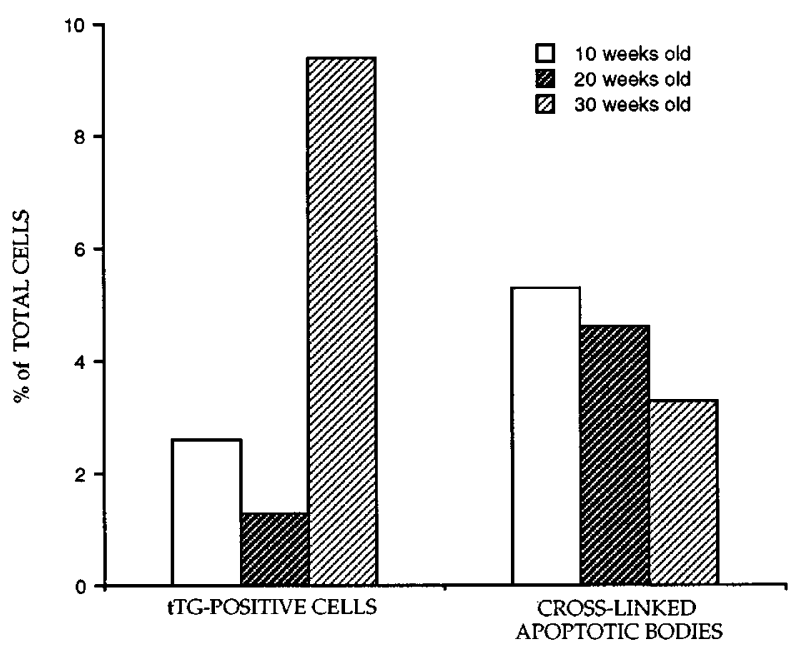

Figure 3 Evaluation of cross-linked apoptotic bodies in MRL/pr/lpr mice. The percentage of apoptotic cells was evaluated by counting the tTG positive cells showing the typical morphology (shrunken cells with condensed chromatin) as well as the cross-linked apoptotic bodies scored at light microscopy (Laborlux D; Leitz, Wetzlar, Germany) over 1000 total cells (including the apoptotic ones). In order to avoid subjective bias, the counts were carried out by different workers and the results pooled. gene in MRL/pr/lpr mice, Southern analysis of genomic DNA from CBA, MRL+/+ and MRL/pr/lpr mice was carried out using a mouse tTG cDNA probe. The Southern analysis of genomic DNA from all animals analyzed did not show extra bands in BamHI, EcoRI and pStl digested DNAs indicating that there is no rearrangement of the tTG gene (data not shown).

To determine in which cells the abnormal accumulation of tTG protein observed in Ipr mice takes place, the localization of the enzyme protein in the thymuses and lymph nodes obtained from young and old CBA, MRL+/+ and MRL/pr/lpr mice was analyzed. Figure 4 shows that accumulation of tTG protein in autoimmune mice occurred mainly in the stromal cells which form the basic architecture of lymphoid organs (Ibrahim et al, 1995).

\section{Establishment and characterization of L929 cell lines overexpressing tTG}

In order to study the possible consequences of the accumulation of an inactive tTG in dying cells, an in vitro model system was established. L929 cells were cotransfected with the neomycin resistance gene (Neo) and an expression vector containing the human tTG CDNA, both driven by an SV40 early gene promoter. As previously reported in other cell lines (Melino et al, 1994; Gentile et al, 1992), the relative frequency of stably transfected tTG clones obtained was quite low and a high rate of spontaneous apoptosis was observed in the transfected cells. Two established clones were used (TG7 and TG8) for further studies along with a clone containing only Neo. The selected clones expressed human TTG mRNA as determined by in situ hybridization (Figure 5) and had high level of the enzyme protein as shown by the strongly positive immunohistochemical reaction with an antibody raised against human tTG (Figure 5). Enzyme activity measurements confirmed that wild type L929 cells and Neo cells have low enzyme activity (Figure 6A). The observed low levels of tTG activity seem to be responsible for the formation of low levels of $\varepsilon-(\gamma$ glutamyl)lysine cross-links detected in cellular protein (Table 2) as well as of the small number of detergent-resistant apoptotic bodies (Figure 6B). The two clones overexpressing tTG had about 5-6 times greater tTG activity (Figure 6A). Similarly, the levels of cross-links in the protein fraction of these cells and the number of detergent resistant apoptotic bodies in the culture were much higher (Table 2 and Figure $6 \mathrm{~B})$.

\section{Effect of TNF $\alpha$ on death, tTG activity and release of L929-derived cell lines}

L929 cells are very sensitive to the cytotoxic action of TNF $\alpha$, which in these cells results in massive cell death with the characteristic morphological and biochemical features of necrosis (Schulze-Osthoff et al, 1994). In our studies, TNF $\alpha$ treatment resulted in a slight increase of transglutaminase activity measured $24 \mathrm{~h}$ after the addition of TNF $\alpha$ (Figure 6A). However, the number of detergent resistant apoptotic bodies was higher in the TG-transfected clones (Figure 6B), suggesting that when the intracellular concentration of tTG 

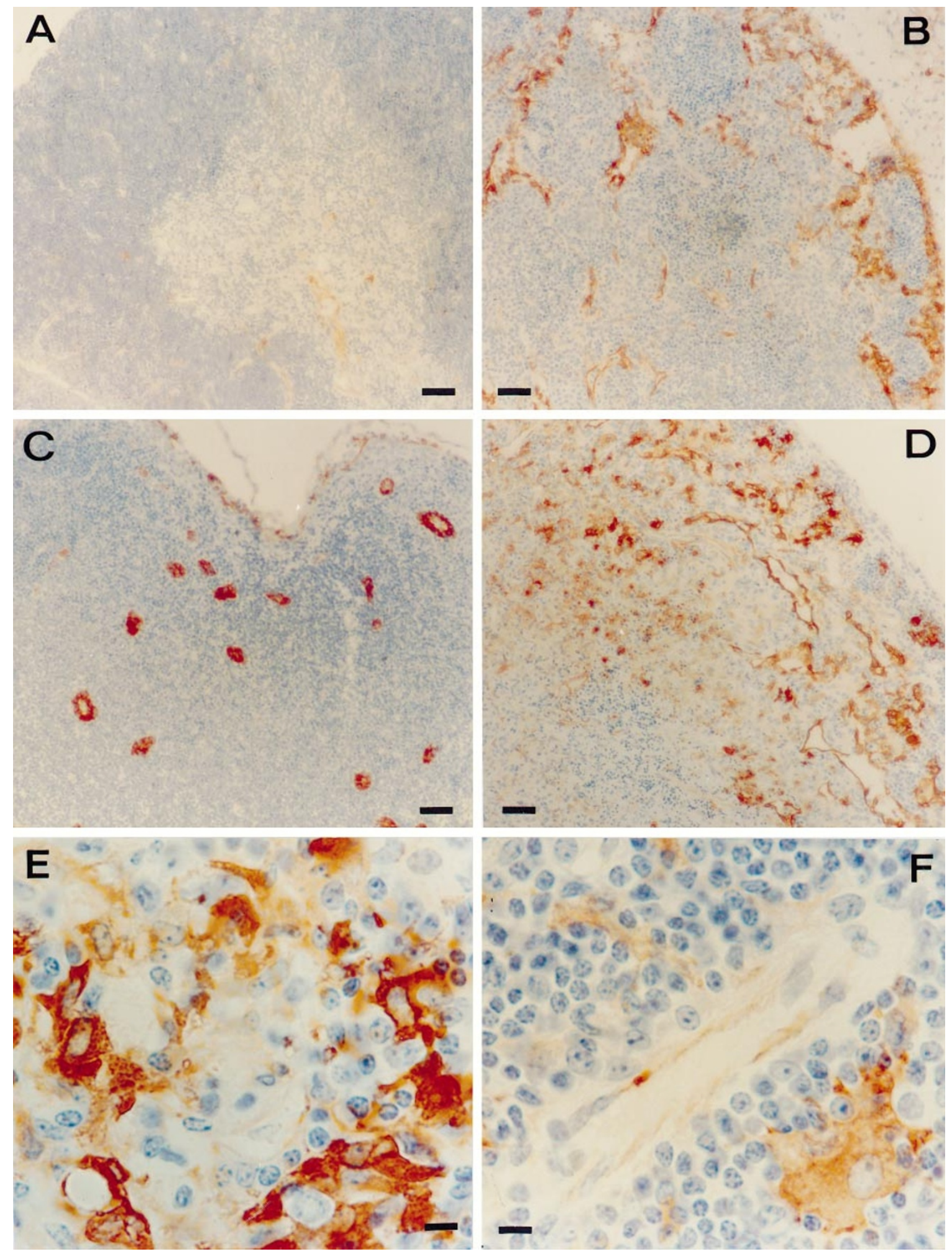

Figure 4 Immunohistochemical localization of tTG protein in thymuses (A-B) and lymph nodes (C-F) from 7 (A, C) and 30 (B,D-F) week-old MRL/pr/lpr-mice. Note the large increase in the tTG-specific staining observed in the cortex of the thymus of an old mouse (B) when compared with that of a young MRL/pr/lpr one (A). In the latter case only endothelial cells are stained by the ITG antibody (arrow heads). A dramatic increase in tTG staining is present in the stromal cells (arrows) of the lymph node of an old mouse (D) when compared with a young MRL/pr/lpr one (C). Panel $\mathbf{D}$ and $\mathbf{E}$ show a greater magnification of the lymph node from 30 week-old MRL/pr/lpr mice. Note the positivity of many polymorphic follicular dendritic-like cells $(\mathbf{E}-\mathbf{F})$. Bars: $(\mathbf{A}-\mathbf{D})=80 \mu \mathrm{m} ;(\mathbf{D}-\mathbf{F})=10 \mu \mathrm{m}$. 
is sufficient, cross-linked apoptotic bodies are formed even when cells die by necrosis. The high concentration of $\varepsilon(\gamma$ glutamyl)lysine cross-links in the TNF $\alpha$ treated tTG clones supports this notion (Table 2).
A key feature distinguishing necrosis and apoptosis is the leakage of intracellular macromolecules in the former and the retaining of these molecules in the apoptotic bodies in the latter (Fesus et al, 1991, Piacentini et al, 1994). L929
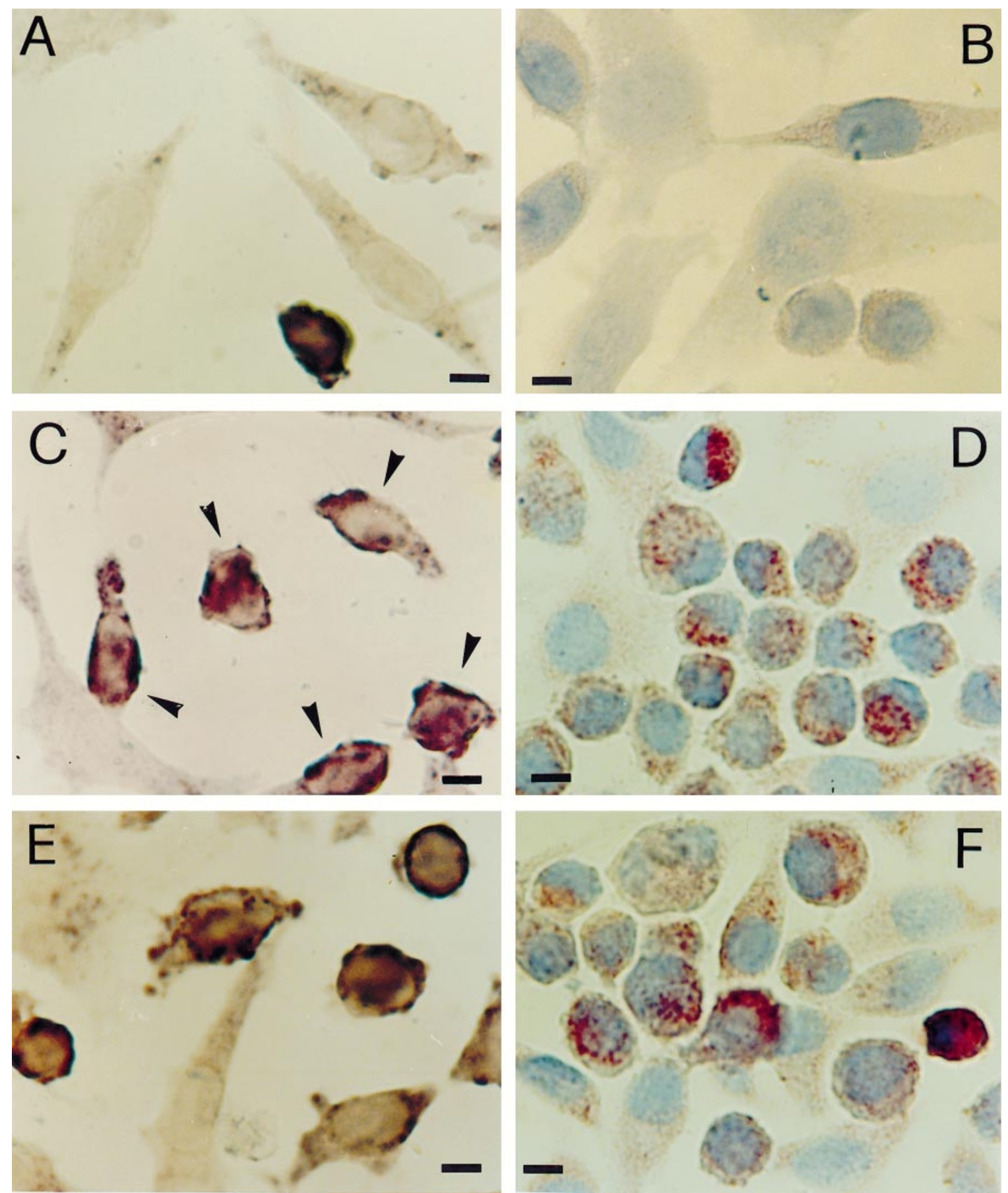

Figure 5 tTG expression in L929 transfected cells. L929 cells were transfected with pSV2Neo plasmid only $(\mathbf{A}-\mathbf{B})$ or cotransfected with pSV2Neo and pSG5TGase constructs $(\mathbf{C}-\mathbf{D}-\mathbf{F})$ and $\mathrm{TTG}$ expression was analyzed by in situ hybridization $(\mathbf{A}-\mathbf{C}-\mathbf{E})$ and immunohistochemistry $(\mathbf{B}-\mathbf{D}-\mathbf{F})$. Hybridization was carried out using a digoxygenin-labelled probe (human ITG CDNA), as described in Materials and Methods and immunocytochemically visualized by anti-digoxygenin Fab fragment labelled with alkaline phosphatase and colorimetric reaction. Note the absence of staining in viable substrate-adherent cells transfected with pSV2Neo plasmid only (A-arrows), and the intense positivity of cells cotransfected with the pSG5-TGase construct (C,E). The clone 7 (C-D) shows the presence of a high level of strongly positive apoptotic bodies (C, arrow heads), while the clone $8(\mathbf{E}-\mathbf{F})$ shows a lower level of tTGmRNA expression with respect to the clone 7 , but always higher than the controls (compare $\mathbf{A}$ and $\mathbf{E}$ ). Interestingly, the staining increased in parallel with the shrinkage typical of cells dying by apoptosis $(\mathbf{C})$ Bars $=$ $7 \mu \mathrm{m}$. 
cells and their derived Neo clone lose a substantial portion of both their cytoplasmic and nuclear constituents during TNF $\alpha$-induced necrotic-lytic death as detected by measuring the release of $\mathrm{LDH}$ and DNA into the extracellular space (Figure $7 \mathrm{~A}$ and $\mathrm{B}$, respectively). Despite the observed increased apoptotic rate (Table 2 and Figure $6 \mathrm{~B}$ ), the leakage of macromolecules was largely reduced in the tTGtransfected clones (Figure $7 \mathrm{~A}$ and $\mathrm{B}$, respectively).
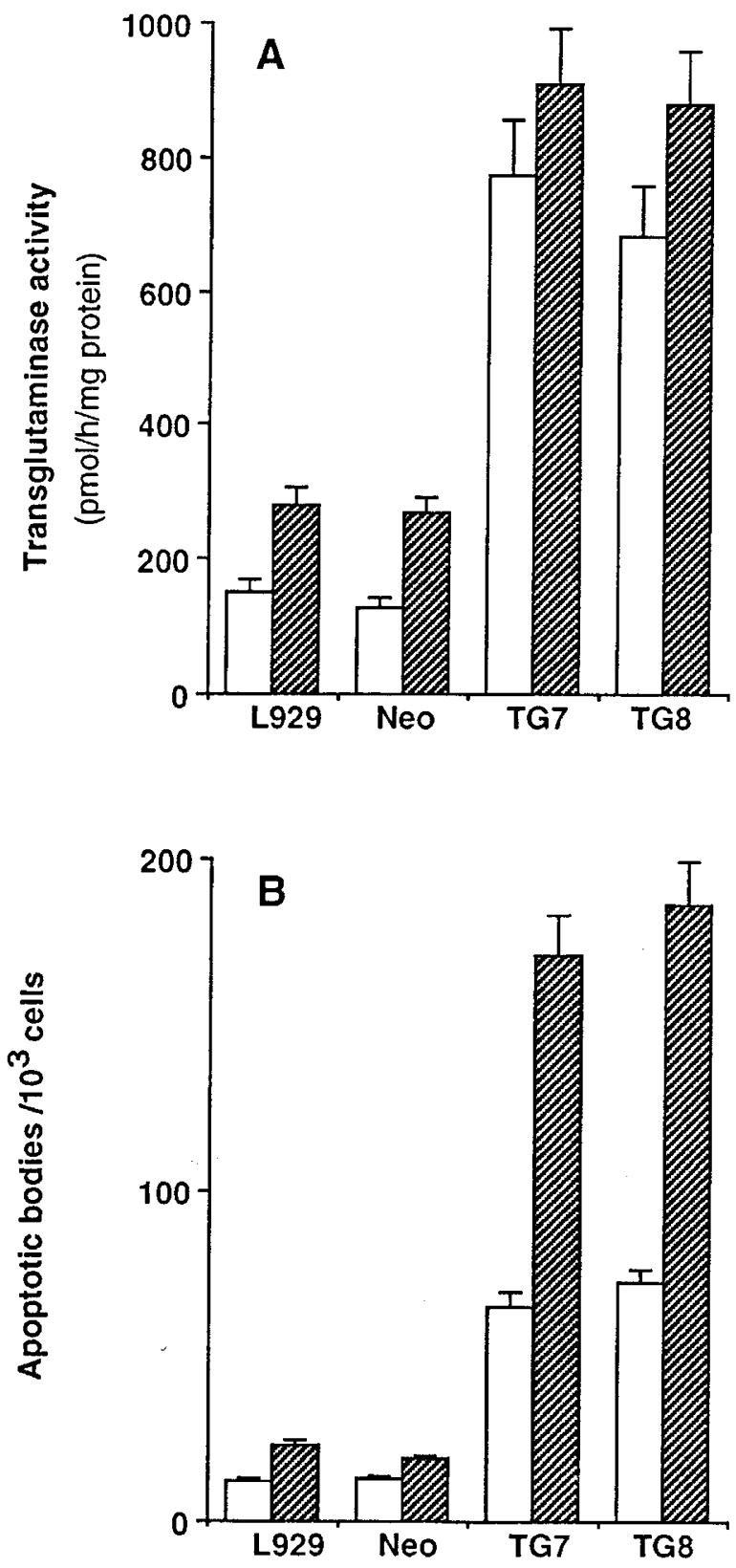

Figure 6 Effect of ectopic expression of tTG on apoptosis rate in L929 cells. Cells cultured as described in the Materials and Methods section were leave untreated $(\square)$ or treated with $250 \mathrm{IU} / \mathrm{ml}$ of TNF $\alpha(\mathbb{Z Z A})$ for $24 \mathrm{~h}$ and $\mathrm{TTG}$ activity and the aoptotic index were measured. (A) In vitro tTG activity was measured as pmoles of $\left[{ }^{3} \mathrm{H}\right]$ putrescine incorporated into protein/hour/mg protein. (B) tTG-dependent formation of cross-linked apoptotic envelopes was evaluated at the light microscope as described in Materials and Methods. Data are the mean of triplicate determinations with a S.E.M. in three different experiments.
However, when the tTG-transfected cells (Figure 7A and B) were treated with TNF $\alpha$ in the presence of a mechanismbased inhibitor of TG activity (which inhibits the intracellular formation of protein bound $\varepsilon(\gamma$-glutamyl)lysine cross-links; Table 1), the release of DNA and LDH from cells was again notably high (Killackey et al, 1989; Burton, 1956).

\section{Detection of LDH in the blood of autoimmune MRL Ipr/lpr mice}

In order to verify as to whether these in vitro findings reflected of a real in vivo pathological condition we analyzed the LDH levels during the development of autoimmunity in MRL $/ p r / l p r$ mice. Table 3 shows that mice bearing the mutation in the CD95 receptor indeed have much higher LDH levels in the plasma when compared to control mice. It is important to note that this increased $\mathrm{LDH}$ release was detected in young mice (7 weeks old) which already displayed a reduced tTG specific activity (Table 1), but do not yet present circulating tTG autoantibodies, lymphadenopathy, glomerulonephritis, arteritis and arthritis occurring with the development of the autoimmune syndrome.

\section{Discussion}

The biological importance of apoptosis and the role of its perturbance in several human diseases (Thompson, 1995) has recently elicited a great deal of interest in defining the biochemical mechanisms which control the initiation of this complex cellular phenomenon (Fesus et al, 1991; Piacentini et al, 1994). By contrast, much less attention has been focused on the biochemical events characterizing the late stages of apoptosis, even though they have fundamental importance in achieving a controlled and 'social' execution of the cell (Kerr, 1995). In this study we show that the presence of a functional tTG activity is necessary for a correct program of apoptosis. A peculiar feature of cells dying by apoptosis is the maintained cellular integrity before phagocytosis and the subsequent degradation by adjacent cells. The biochemical processes underlying the structural changes occurring in the cytoplasm of apoptotic cells are still largely unknown. We have demonstrated here that tTG-catalyzed intracellular protein crosslinking plays an important role in increasing the stability of apoptotic bodies and the consequent reduction of leakage of their contents. In fact, overexpression of tTG is able to reduce

Table $2 \varepsilon(\gamma$-glutamyl)lysine concentration in the protein fraction of wild type and tTG-transfected L929 cells following treatment with TNF $\alpha$ and/or a tTG inhibitor

\begin{tabular}{|c|c|c|c|c|}
\hline \multirow[b]{2}{*}{ Treatments } & \multicolumn{3}{|c|}{ tTG } & \multirow{2}{*}{$\begin{array}{l}\text { TNF } \alpha+\text { tTG } \\
\text { inhibitor }\end{array}$} \\
\hline & None & inhibitor & TNF $\alpha$ & \\
\hline L929 & $305 \pm 41$ & $228 \pm 30$ & $383 \pm 39$ & $262 \pm 27$ \\
\hline $\mathrm{Neo}$ & $275 \pm 41$ & $230 \pm 27$ & $363 \pm 34$ & $268 \pm 22$ \\
\hline TG 7 & $950 \pm 82$ & $439 \pm 54$ & $3805 \pm 223$ & $1486 \pm 297$ \\
\hline TG 8 & $870 \pm 69$ & $474 \pm 66$ & $4165 \pm 318$ & $1379 \pm 287$ \\
\hline
\end{tabular}

Cells cultured as described in the Materials and Methods section were treated with $250 \mathrm{IU} / \mathrm{ml}$ of TNF $\alpha$ and/or the transglutaminase inhibitor $(200 \mu \mathrm{M}$; Syntex RS 71666-007) for 24 h. $\varepsilon(\gamma$-glutamyl)lysine concentration was detected after exhaustive proteolytic digestion of the protein fraction as previously reported (Fesus et al., 1991; Harsfalvi et al., 1992). Data are expressed as pmol/mg protein and are the mean with a S.E.M. of four different experiments. 

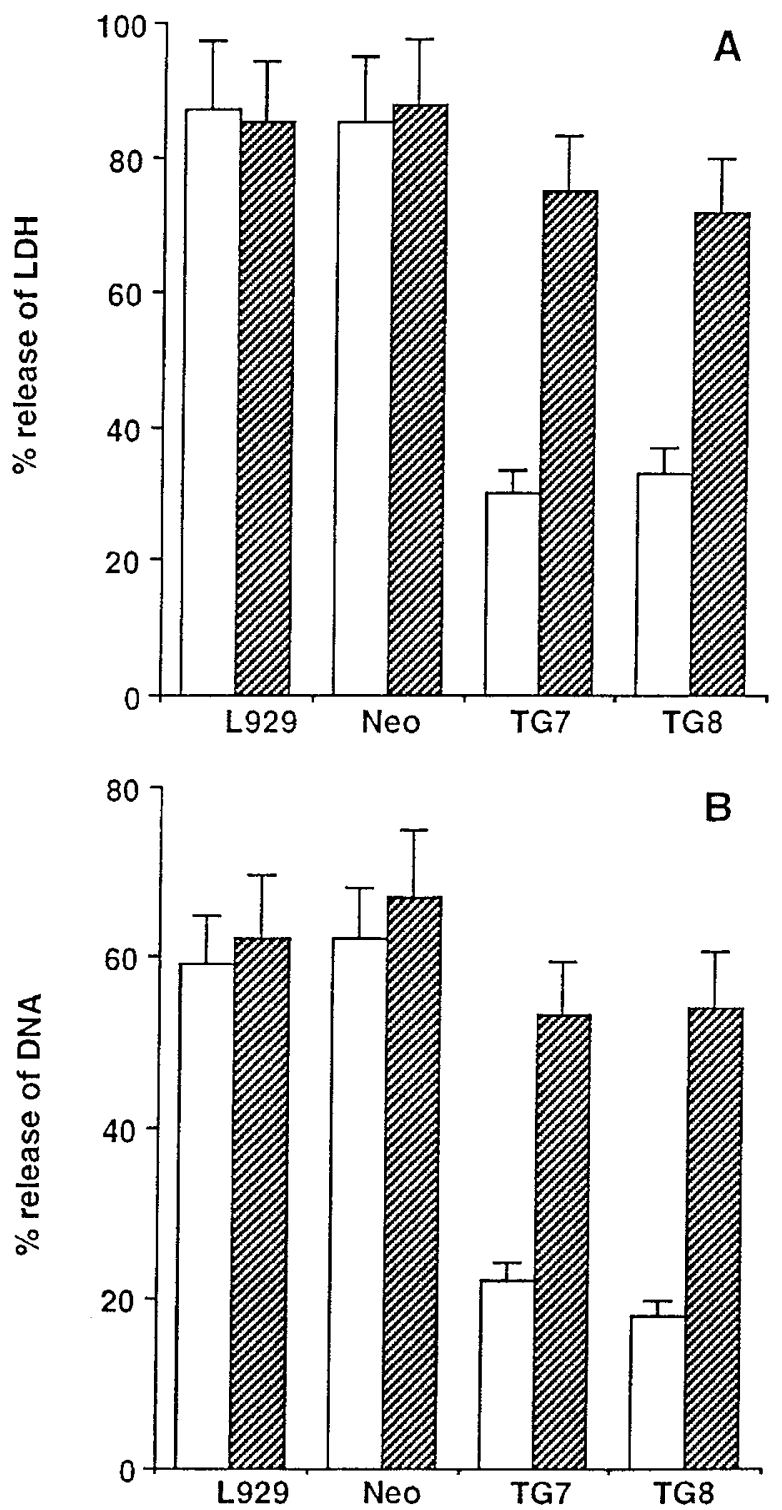

Figure 7 Effect of TNF $\alpha$ on the LDH and DNA release in tTG-transfected L929 cells. Cells cultured as described in the Materials and Methods section were treated with $250 \mathrm{IU} / \mathrm{ml}$ of TNF $\alpha$ alone $(\square)$ or in the presence of (V/A) transglutaminase inhibitor $(200 \mu \mathrm{M}$; Syntex RS $71666-007)$ for $24 \mathrm{~h}$ and LDH (A) and DNA (B) release quantified as previously described. Data are the mean of triplicate determinations with a S.E.M. in four different experiments.

Table 3 Effect of aging on LDH levels in the blood of MRL+/+ and MRL/pr/lpr mice

\begin{tabular}{lcc}
\hline Age & \multicolumn{2}{c}{ LDH $^{*}$} \\
(weeks) & MRL+/+ & MRLIpr/lpr \\
\hline 7 & $1.3 \pm 0.4$ & $10.0 \pm 0.5^{\circ}$ \\
30 & $0.8 \pm 0.3$ & $7.1 \pm 0.3^{\circ}$ \\
\hline
\end{tabular}

$\left(^{*}\right) \mathrm{LDH}$ enzymatic activity is expressed as $\mathrm{mU} / \mathrm{mg}$ protein and was measured as described by Howell et al (1979). Data are the mean of triplicate determinations with a S.E.M. in four different animals. $\left(^{\circ}\right)$ Statistically significant $(P<0.01)$ with respect to the $M R L+/+$ mice. the release of macromolecules (DNA and LDH) characterizing TNF $\alpha$-induced necrotic death of L929 cell line. This protective effect is abolished when the crosslinking activity of the enzyme is blocked by a specific inhibitor. The biological relevance of protein cross-linking is particularly evident in the programmed death of keratinocytes in squamous epithelia. In these cells various substrate proteins (involucrin, loricrin and others) are cross-linked by specific transglutaminases to form an intracellular protein 'envelope', beneath the plasma membrane of the dying corneocyte: the structure which isolates and protects our organism from external insults (Polakowska and Haake, 1994; Steinert, 1995).

MRL/pr/lpr mice have abnormally high levels of TNF $\alpha$ (Nagata and Golstein, 1995, Izui et al, 1984) which, in the presence of low levels or inactive tTG detected in these animals, might lead to lytic death similar to necrosis in some cells. Hence, at both the cellular and the molecular levels, the autoimmune pathology observed in MRL/pr/lprmice seems to reproduce various aspects of the necrotic death described in L929 cells in vitro (Schulze-Osthoff et al, 1994), suggesting that release of macromolecules from cells lacking ITG may indeed take place in these autoimmune mice. We have shown here, that the accumulation of autoantibodies against tTG, $70 \mathrm{kDa}$ HSP and dsDNA takes place only in old MRL/pr/ Ipr mice, while increased LDH levels are already detectable in the blood of young MRL/pr/lpr mice. These findings suggest that the continuous presence of circulating intracellular autoantigens, very likely due to a necrotic versus an apoptotic form of death, might contribute to the development of autoantibodies observed in old MRL/pr/lpr mice. In fact, a massive autoimmune response, such as that of MRL/pr/lpr mice, requires a long lasting defective stimulation of the immune system (Theofilopoulos, 1995); which, for apoptosis impairment, may be partially explained by the CD95 mutation and the presence of an inactive tTG. However, the early deregulation of other elements of the immune system is very likely required to fully explain the molecular basis of a complex disease such systemic autoimmunity. It is interesting to note that the presence of increased levels of plasmatic $\mathrm{LDH}$ has also reported in a human autoimmune syndrome (Gemma et al, 1992).

In addition to tTG and dsDNA, the presence of autoantibody to lipocortin-1 (LC1) has also recently been demonstrated in the autoimmune-prone MRL mice (Ikai et al, 1992). LC1 is a well characterized tTG substrate, which is induced during apoptosis (McKanna, 1995; Ando et al, 1989). LC1 specifically binds to $\mathrm{Ca}^{2+}$ and phosphatidylserine and displays marked anti-inflammatory and immunosuppressive features (McKanna, 1995; Ando et al, 1989). The affinity for $\mathrm{Ca}^{2+}$ - and phosphatidylserine and consequently the biological activity of LC1 are regulated by its tTG-dependent polymerization (Ando et al, 1989). Hence, the lack of a functional tTG, observed in the autoimmune MRL/pr/lpr mice, may lead to the inhibition of LC1 biological activity with marked effects on inflammation and autoimmune responses. In addition, the phagocytosis of apoptotic cells involves the recognition of phosphatidylserine specifically exposed on the surface of dying cells (Savill et al, 1993). Since, polymerized-LC1 specifically binds to phosphatidylserine, an important role for this tTG substrate 
in the clearance of apoptotic cells may be also envisaged. Future studies should rule out whether the absence of the tTG-dependent polymerization of LC1 might have a role in the abnormal accumulation of 'preapoptotic' cells in the lymphoid organs of autoimmune MRL/pr/lpr mice (Van Houten and Budd, 1992).

The abnormal accumulation of tTG in viable accessory cells of lymphoid tissues suggests a generalized disregulation of apoptosis in the immune system of MRL/pr/lpr mice. An important role for the L3T4 T lymphocyte subset in the development of autoimmunity in Ipr mice has been proposed (Santoro et al, 1988). This specific inducer/helper autoreactive $T$ cell clone once activated by antigen presenting cells (APCs) expressing the appropriate la allele and antigen, autonomously kills its target APC (Ju et al, 1986). Thus, in the absence of a functional CD95 receptor in Ipr mice this subset of $T$ cells might deliver an incomplete death signal leading to partial induction of the apoptotic program which involves the expression of an inactive tTG in stromal cells.

Two possible explanations for the presence of catalytically-inactive tTG can be hypothesized. Nakaoka et al. (1994) have demonstrated that tTG is the $74 \mathrm{kDa}$ subunit $\left(G_{\alpha h}\right)$ associated with the $50 \mathrm{kDa} \beta$ subunit $\left(\mathrm{G}_{\beta \mathrm{h}}\right)$ of the $\mathrm{G}_{\mathrm{h}}$ protein (Nakaoka et al, 1994). Thus, the $G_{\alpha h}$ is a multifunctional protein which, by binding GTP in a $\mathrm{G}_{\alpha \mathrm{hGTP}}$ complex, modulates receptor-stimulated phospholypase-C (PLC) activation and inhibits its transglutaminase activity which is needed to prevent the release of macromolecules from cells dying by apoptosis. tTG-catalyzed reactions result in post-translational modification of proteins by establishing $\varepsilon(\gamma$-glutamyl)lysine cross-linkings and/or covalent incorporation of di- and polyamines into proteins (Folk, 1980; Piacentini et al, 1994). Diamines and polyamines may also participate in cross-linking reaction through the formation of $\mathrm{N}, \mathrm{N}$-bis $(\gamma$-glutamyl)polyamine cross-bridges (Folk, 1980; Piacentini et al, 1994). We demonstrated that high intracellular levels of putrescine, spermidine and spermine might impair the stabilizing cross-linking activity of tTG by favouring the formation of mono $(\gamma$-glutamyl)polyamine derivatives (Piacentini et al, 1990). Consistent with this hypothesis increased levels of di- and polyamines during the development of autoimmunity in $\mathrm{MRL} / p r / / p r$ mice have recently been demonstrated (Hsu et al, 1994).

In conclusion, these studies indicate that deregulation of the cell death program plays a critical role in the development of autoimmunity. In addition to the defect in the CD95 system, we have shown that the impairment of other apoptosis-related gene products, such as tTG, may be one of the component in the complex mechanism leading to the production of self-antigens and to autoimmune responses.

\section{Materials and Methods}

\section{Chemicals}

$\left\{1,4(\mathrm{n})-{ }^{3} \mathrm{H}\right\}$ putrescine dihydrochloride $(26.3 \mathrm{Ci} / \mathrm{mmol})$ was obtained from Amersham, Bucks, UK). Optifluor was obtained from Packard (Zurich, Switzerland). N,N'-dimethylcasein, bovine serum albumin, putrescine hydrochloride and dexamethasone were from Fluka (Buchs, Switzerland). Strepavidin-Biotin immunoperoxidase staining systems were from Biogenex (USA). Tumor Necrosis Factor- $\alpha$ (TNF $\alpha$ ) and cell culture reagents were from Sigma (St. Louis, USA). The mechanism-based transglutaminase inhibitor (RS 71666-007) was obtained from Syntex Research, Canada (Castelhano et al, 1998; Killackey et al, 1989). Other chemicals were of reagent grade and used without further purification. DNA release was measured as described previously (Burton, 1956). Lactate dehydrogenase activity was determined by an UV kinetic method using a commercial kit supplied by Sigma (St. Louis, USA).

\section{Cell cultures and transfection}

L929 murine cells were grown in RPM-I 1640 medium supplemented with $10 \%$ (vol/vol) heat-inactivated fetal calf-serum, 2 mM L-glutamine, $2 \mathrm{~g}$ bicarbonate per liter, in a humidified atmosphere with $5 \%$ (vol/vol) $\mathrm{CO}_{2}$ at $37^{\circ} \mathrm{C}$. L929 cells were transfected with pSV2Neo or cotransfected with pSG5-TGsense and PSV2Neo constructs as described previously (Melino et al, 1994). For selection, cells were cultured in the presence of $0.8 \mathrm{mg} / \mathrm{ml}$ of G418 and cell clones were obtained from individual G418-resistant colonies. Cells cultured were treated with $250 \mathrm{IU} / \mathrm{ml} \mathrm{TNF} \alpha$ and/or with $200 \mu \mathrm{M}$ transglutaminase inhibitor (RS 71666-007) for $24 \mathrm{~h}$.

\section{Mice}

The following mouse strains were used: MRL/Mp-Ipr/lpr (MRL/pr/lpr), MRL/Mp-+/+ (MRL+/+) and CBA at 7, 10, 20, 30, 50 weeks of age. All mice were obtained from Cave-Tech Breeding Unit and were maintained as continuously breeding colonies in the local animal facility. Sera were prepared on Microtainer (Becton Dickinson, Mountain View, CA) from blood taken from animals under anesthesia by cutting of subclavian vein and brachial artery, aliquoted and stored at $-20^{\circ} \mathrm{C}$ until use.

\section{Enzyme linked immunosorbent assay (ELISA)}

Microtiter plates (Becton Dickinson) were coated overnight at room temperature with purified human red blood cell tTG (Fesus and Arato, 1986) or with the peptide corresponding to the residues 235-249 of Heat Shock Protein (70-HSP-01): amino acid sequence NRLVNHFVEEFKRKH, purity more than $90 \%$ by HPLC analysis. For anti-dsDNA microplates were coated with $100 \mu \mathrm{l} /$ well of poly L-Lys (Sigma, USA) at the concentration of $5 \mu \mathrm{g} / \mathrm{ml}$ for $1 \mathrm{~h}$ at room temperature; after five washes in plates, $100 \mu \mathrm{l}$ of fetal bovine thymus dsDNA (Sigma, USA) were diluted in phosphate buffer saline (PBS) at a concentration of $1 \mu \mathrm{g} /$ well in $100 \mu \mathrm{l}$ of $0.05 \mathrm{M}$ sodium carbonate buffer, $\mathrm{pH}$ 9.5. Coated plates were washed five times with $0.9 \% \mathrm{NaCl}$ containing $0.05 \%$ Tween 20 . Mouse sera, diluted $1: 100$ with PBS containing $0.5 \%$ bovine serum albumin, $0.05 \%$ Tween 20 , were added to coated wells and incubated at $37^{\circ} \mathrm{C}$ for $60 \mathrm{~min}$. After washing a peroxidase-labeled goat anti-mouse Ig (BIO-RAD, USA, recognizing heavy and light chain of $\operatorname{lgG}$ ), diluted $1: 2000$ was added. All incubations were performed at $37^{\circ} \mathrm{C}$ for $60 \mathrm{~min}$, followed by five washes. After the last incubation, horseradish peroxidase substrate (1,2-phenylenendiamine, DAKO, Denmark) in citrate-phosphate buffer, $\mathrm{pH} 5$, and $0.015 \% \mathrm{H}_{2} \mathrm{O}_{2}$ was added and allowed to react for $30 \mathrm{~min}$ at $37^{\circ} \mathrm{C}$; reaction was stopped by adding $50 \mu \mathrm{l} 1 \mathrm{M} \mathrm{HCl}$, and the light absorbance was determined at $490 \mathrm{~nm}$ in an ELISA reader (BIORAD, USA). Results were expressed as the mean \pm standard error of at least three determinations for each experimental group. 


\section{'Tissue' transglutaminase assay}

Thymuses and lymph nodes from CBA mice (7 and 50 weeks old), MRL+/+ and MRL/pr/lpr mice (7 and 30 weeks old) were washed extensively with PBS (without $\mathrm{Ca}^{2+}$ and $\mathrm{Mg}^{2+}$ ) and homogenized in $0.1 \mathrm{M}$ Tris- $\mathrm{HCl}, \mathrm{pH} 7.5$, containing $0.25 \mathrm{M}$ sucrose, $0.5 \mathrm{mM}$ EDTA, $1 \mathrm{mM}$ PMSF. L929 cells after different treatment were mechanically removed from flasks, washed with PBS and sonicated at $4^{\circ} \mathrm{C}$ for $20 \mathrm{~s}$. TTG activity was measured by detecting the incorporation of $\left[{ }^{3} \mathrm{H}\right]$ putrescine into $\mathrm{N}, \mathrm{N}$ '-dimethylcasein as previously reported (Piacentini et al, 1986). Protein concentration was determined using bovine serum albumin as standard.

\section{In situ hybridization}

Fixation of tissue culture cells L929 cells transfected with pSV2Neo plasmid or cotransfected with pSV2Neo and pSG5TGSense were grown for 3 days on coverslips, removed from the growth media and fixed in a freshly prepared $4 \%$ paraformaldeyde.

tTG DNA probe A $3.4 \mathrm{~Kb}$ fragment containing mouse tissue transglutaminase was used as cDNA probe (pmT700pU probe), labelled by the incorporation of digoxygenin-labelled deoxyuridine triphosphate (Dig-dUTP) (Boehringer Mannheim, Germany) by random prime DNA labelling. To check the activity of the probe, it was diluted in distilled water $(5 \mathrm{ng}-0.1 \mathrm{pg} / 50 \mu \mathrm{l})$ spotted onto nitrocellulose filters and visualized immunoenzymatically as described below.

Hybridization and detection of hybridized $T T G$ probe In situ nucleic acid hybridization was performed according to the method described by Brigati et al (1983) with minor variations.

Samples were overlaid with $10 \mu \mathrm{l}$ of prehybridization buffer $(50 \%$ Formammide, $5 \times$ Denhardt's, $100 \mu \mathrm{g} / \mathrm{ml}$ carrier salmon sperm DNA in $6 \times \mathrm{SSC}$ ) for $15 \mathrm{~min}$ at $42^{\circ} \mathrm{C}$. Following prehybridization, the labelled probe $(2 \mu \mathrm{g} / \mathrm{ml})$ was denaturated by heating at $85^{\circ} \mathrm{C}$ for 6 min and then added in hybridization mixture and allowed to hybridize for $12 \mathrm{~h}$ at $45^{\circ} \mathrm{C}$. After hybridization, the coverslips were carefully removed and samples were washed at $37^{\circ} \mathrm{C}$ in $2 \times$ SSC, $2 \times$ SSC, $0.1 \times$ SSC for 15 min each.

Subsequently samples were processed for detection using a polyclonal antidigoxigenin Fab fragment from sheep labelled with alkaline phosphatase (Boehringer). The colorimetric reaction was developed with nitroblue tetrazolium salt as alkaline phosphatase substrate. The development of a dark purple coloured precipitate at the enzyme site was monitored by microscopic examination.

\section{Western blot analysis}

Determination of tTG protein was carried out on lymph nodes and thymuses from CBA mice ( 7 and 50 week-old), MRL+/+ and MRL/pr/lpr mice (7 and 30 week-old). Extracts ( $100 \mu \mathrm{g}$ of total protein) were run on 10.5\% SDS-PAGE (Melino et al, 1994). The gel was electroblotted onto nitrocellulose paper at $40 \mathrm{~mA}$ overnight. tTG positive bands were revealed by utilizing an affinity purified IgG raised in rabbits against human TTG as a primary antibody and, horseradish peroxidase conjugated goat anti-rabbit IgG (BIO-RAD, USA) as a secondary antibody. The reaction was developed by the chemoluminescence ECL detection system (Amersham, UK).

\section{Immunohistochemistry}

Immunohistochemical staining was performed using an affinity purified monospecific IgG raised in rabbits against human red blood cell soluble tTG $(1: 100)$ as a primary antibody (Fesus and Arato, 1986).
Incubations with the primary antibody were carried out in a wet chamber overnight at $4^{\circ} \mathrm{C}$. A biotinylated goat anti-rabbit IgG was used as secondary antibody, followed by a preformed strept-avidinhorseradish peroxidase complex (BioGenex, USA). The reaction was developed using aminoethylcarbazole (AEC), (CRL, USA) as chromogen substrate and $0.01 \% \mathrm{H}_{2} \mathrm{O}_{2}$. Slides were counterstained in Mayer's haematoxylin. Endogenous peroxidase activity was blocked by methanol- $\mathrm{H}_{2} \mathrm{O}_{2}$.

\section{Evaluation of the apoptotic index}

To estimate the apoptotic index in lymph node from 10, 20 and 30 weeks old MRL/pr/lpr mice, cells freshly isolated were smeared on slides and fixed with $2.5 \%$ paraformaldehyde and immunostained by anti-tTG antibody. The percentage of apoptotic cells was evaluated by counting the TTG positive cells showing the typical morphology (shrunken cells with condensed chromatin) as well as the cross-linked apoptotic bodies scored at light microscopy (Fesus et al, 1989) Laborlux D; Leitz, Wetzlar, Germany) over 1000 total cells (including the apoptotic ones). In order to avoid subjective bias, the counts were carried out by different workers and the results pooled.

\section{$\varepsilon(\gamma$-glutamyl)lysine measurement}

$\varepsilon(\gamma$-glutamyl)lysine measurement was carried out according to a previously published method (Fesus et al, 1991; Harsalvi et al, 1992). A preliminary purification of amino acids and peptides was achieved by eluting aliquots of the plasma samples on ion-exchange chromatography and on silica column. Separation of amino acids and peptide derivatives was carried out by HPLC on a mBundapack $\mathrm{C} 18$ column upon derivativization with phenylisothiocyanate (PITC); ${ }^{3} \mathrm{H}$-labelled $\varepsilon(\gamma$-glutamyl)lysine was used as an internal standard throughout the procedure. The quantification of $\varepsilon(\gamma$-glutamyl)lysine in the plasma was based on peak area as compared to those obtained from a standard amount of the $\varepsilon(\gamma$-glutamyl)lysine (Serva; Germany) and on the recovery determined by isotope dilution.

\section{Acknowledgements}

The authors would like to express their gratitude to Professor F. Autuori for stimulating discussions and encouragement. This work was supported by EU Biotechnology Program; the Italian AIDS Research Project; AIRC; the Hungarian Ministry of Welfare T-01 408/1993 and the ItalianHungarian Project Fund V/3. M. Piacentini and L. Fesus have contributed equally to this work.

\section{References}

Ando Y, Immamura S, Owada MK, Kakunaga Tand Kannagi R(1989)Cross-linking of lipocortin 1 and enhancement of its $\mathrm{Ca}^{2+}$ sensitivity by tissue transglutaminase. Biochem. Biophys. Res. Commun. 163: 944-950

Brigati DJ, Myerson D, Leary JJ, Spalholz B, Travis SZ, Fong CKY, Hsiung GD and Ward DC (1983) Detection of viral genomes in cultured cells and paraffinembedded tissue sections using biotin-labeled hybridization probes. Virology 126: $32-50$

Burton K (1956) A study of conditions and mechanisms of a diphenylamine reaction for a colorimetric estimation of deoxyribonucleic acid. Biochem. J. 62: 315-322

Buttyan R, Zakeri Z, Lockshin R and Wolgemuth D (1988) Cascade induction of c-fos $\mathrm{c}$-myc and heat shock $70 \mathrm{~K}$ transcripts during regression of the rat ventral prostate gland. Mol. Endocrinol. 2: 650-657

Casthelhano AL, Billedeau R, Pliura DH, Bonaventura B and Kranz A (1988) Synthesis, chemistry and absolute configuration of novel transglutaminase inhibitors containing a 3-halo-4,5-dihydroisoxazole. J. Bioorg. Chem. 16: 335349 
Cohen PL and Eisenberg RA (1991) Lpr and gld: single gene models of systemic autoimmunity and lymphoproliferative disease. Annu. Rev. Immunol. 9: 243269

Fesus $L$ and Arato $G$ (1986) Quantitation of tissue transglutaminase by a sandwich ELISA system. J. Immunol. Methods 94: 131-138

Fesus L, Davies PJA and Piacentini M (1991) Apoptosis: Molecular mechanism in programmed cell death. Eur. J. Cell Biol. 56: 170-177

Fesus L, Tarcsa E, Kedei N, Autuori F and Piacentini M (1991) Degradation of cells dying by apoptosis leads to accumulation of $\varepsilon(\gamma$-glutamyl)lysine isopeptide in culture fluid and blood. FEBS Lett. 284: 109-112

Fesus L, Thomazy V, Autuori F, Cerù MP, Tarcsa E and Piacentini M (1989) Apoptotic hepatocytes become insoluble in detergents and chaotropic agents as a result of transglutaminase action. FEBS Lett. 245: 150-154

Folk JE (1980) Transglutaminases. Ann. Rev. Biochem. 49: 517-531

Gemma R, Suzuki Y, Tanaka I, Taminato T, Yoshimi T and Kanno T (1992) Lactate dehydrogenase (LDH)-linked immunoglobulin in a patient with Graves' disease treated with methimazole. Intern-.Med. 31(3): 377-379

Gentile V, Thomazy V, Piacentini M, Fesus L and Davies PJA (1992) Expression of tissue transglutaminase in BALB-C 3 T3 fibroblasts: effects on cellular morphology and adhesion. J. Cell Biol. 119: 463-474

Harsfalvi J, Tarcsa E, Udvardy M, Zajka G, Szarvas T and Fesus L (1992) Presence and possible origin of $\varepsilon(\gamma$-glutamyl) lysine isopeptide in human plasma Thromb. Haemost. 67: 60-62

Howell BF, McCune S and Schaffer R (1979) Lactate-to-pyruvate reaction: Arrhenius relationships for lactate dehydrogenase: a re-examination. Clin. Chem. 23 $269-272$

Hsu HC, Seibold JR and Thomas TJ (1994) Regulation of ornithine decarboxylase in the kidney of autoimmune mice with the $1 p r$ gene. Autoimmunity 19: 253-264

Ibrahim MAA, Chain BM and Katz DR (1995) The injured cell: the role of dentritic cell system as a sentinel receptor pathway. Immunol. Today 16 : $181-186$

Ikai K, Shimizu K, Kanauchi H, Ando Y, Furukawa F and Immamuira S (1992) The presence of autoantibody to lipocortin 1 in autoimmune-prone MRL mice. Autoimmunity 12: 239

Izui S, Kelley VE, Masuda K, Yoshida H, Roths JB and Murphy ED (1984) Induction of various autoantibodies by mutand gene Iprin several strains of mice. J. Immunol. 133: $227-233$

Ju ST, Dekruyff RH and Dorf ME (1986) Inducer T-cell-mediated killing of antigenpresenting cells. Cell. Immunol. 101: 613-624

Kerr JFR (1995) Neglected opportunity in apoptosis research. Trends Cell Biol. 5 : $55-57$

Killackey JJF, Bonaventura BJ, Castelhano AL, Billedeau RL, Farmer W, Deyoung L, Kranz A and Pliura DH (1989) A new class of mechanism-based inhibitors of transglutaminase enzymes inhibits the formation of cross-linked envelopes by human malignant keratynocytes. Mol. Pharmacol. 35: $701-$ 706

Levine J, Hartwell D and Beller DI (1991) Imbalanced cytokine production by machrophages from autoimmune-prone mice. Immunol. Lett. 0: 183-192

McKanna JA (1995) Lipocortin 1 in apoptosis: mammary regression. Anat. Rec. 242: $1-10$

Melino G, Annichiarico-Petruzzelli M, Piredda L, Candi E, Gentile V, Davies PJA and Piacentini M (1994) 'Tissue' Transglutaminase and apoptosis: sense and antisense transfection studies in human neuroblastoma cells. Mol. Cell. Biol. 14: $6584-6592$
Nagata S and Golstein P (1995) The Fas death factor. Science 267: 1445-1449 Nakaoka H, Perez DM, Baek KJ, Das T, Husain A, Mosono IM and Graham RM (1994) Gh: A GTP-binding protein with transglutaminase activity and receptor signaling function. Science 264: 1593-1596

Piacentini M (1995) 'Tissue' transglutaminase a candidate effector element of physiological cell death. Curr. Top. Microbiol. 200: 163-176

Piacentini M, Autuori F, Dini L, Farrace MG, Ghibelli L, Piredda L and Fesus L (1991) Tissue transglutaminase is specifically expressed in neonatal rat liver cells undergoing apoptosis upon epidermal growth factor-stimulation. Cell Tissue Res. 263: 227-235

Piacentini M, Davies PJA and Fesus L (1994) Tissue transglutaminase in cells undergoing apoptosis. In Apoptosis II: The molecular basis of apoptosis in disease. L.D. Tomei and F.O. Cope editors. Cold Spring Harbor Lab. Press. $143-165$

Piacentini M, Farrace MG, Imparato M, Piredda L and Autuori F (1990) Polyaminedependent post-translational modification of proteins in differentiating mouse epidermal cells. J. Invest. Dermatol. 94: 694-699

Piacentini M, Sartori C, Beninati S, Bargagli AM and Argento Cerù MP (1986) Ornithine decarboxilase, transglutaminase, diamine oxidase and total diamines and polyamines in maternal liver and kidney throughout rat pregnancy. Biochem. J. 234: $435-440$

Polakowska RR and Haake AR (1994) Apoptosis: the skin from a new perspective. Cell Death Differ. 1: 19-31

Santoro TJ, Portanova JP and Kotzin BL (1988) The contribution of L3T4 ${ }^{+}$T cells to lymphoproliferation and autoantibody production in MRL-Ipr/lpr mice. J. Exp. Med. 167: 1713-1718

Savill J, Fadok V, Henson P and Haslett C (1993) Phagocyte recognition of cell undergoing apoptosis. Immunol. Today 14: 131-136

Schulze-Ostoff F, Krammer PH and Droge W (1994) Divergent signalling via APO-1/ Fas and the TNF receptor, two homologous molecules involved in physiological cell death. EMBO J. 13: 4587-4596

Steinert PM (1995) A model for the hierarchical structure of the human epidermal cornified cell envelope. Cell Death Differ. 2: 33-40

Tang B, Matsuda T, Akira S, Nagata N, Ikehara S, Hirano T and Kishimoto T (1991) Age-associated increase in interleuken 6 in MRL/1pr mice. Int. Immunol. 3:273278

Theofilopoulos AN (1995) The basis of autoimmunity: part II genetic predisposition. Immunol. Today 16: 150-159

Thompson CB (1995) Apoptosis in the pathogenesis and treatment of disease. Science 267: 1456-1462

Van Houten N and Budd RC (1992) Accelerated programmed cell death of MRL-Ipr/ IprT lymphocytes. J. Immunol. 149: 2513-2517

Watanabe-Fukunaga R, Brannan Cl, Copeland NG, Jenkins NA and Nagata S(1992) Lymphoproliferation disorder in mice explained by defects in Fas antigen that mediates apoptosis. Nature 356: $314-317$

White E (1996) Life, Death, and pursuit of apoptosis. Genes Dev. 10: 1-15

Wyllie AH, Kerr JFR and Currie AR (1980) Cell death the significance of apoptosis. Int Rev. Cytol. 68: 251-306

Yokoyama H, Kreft B and Kelly VR (1995) Biphasic increase in circulating and renal TNF-alpha in MRL-Iprmice with differing regulatory mechanisms. Kidney Int. 47: $122-130$ 